\title{
Validation of the verbal and social interaction questionnaire for nursing students-The focus of nursing students in their relationship with patients
}

\author{
Mikael Rask*1, Albinsson Gunilla ${ }^{1}$, Safipour Jalal ${ }^{1}$, Wenneberg Stig ${ }^{1}$, Andersson Lisbet ${ }^{1}$, Carlsson Blomster Monica ${ }^{1}$, \\ Ozolins Lise-Lotte ${ }^{1}$, Borg Christel ${ }^{1,2}$, Lindqvist Gunilla ${ }^{1}$ \\ ${ }^{1}$ School of Health and Caring Sciences, Linnaeus University, Växjö, Sweden \\ ${ }^{2}$ Department of Health, Blekinge Institute of Technology, Karlskrona, Sweden
}

Received: September 19, 2017

Accepted: November 28, 2017 Online Published: December 6, 2017

DOI: $10.5430 /$ jnep.v8n4p81

URL: https://doi.org/10.5430/jnep.v8n4p81

\begin{abstract}
The Verbal and Social Interaction Nursing Students questionnaire (VSI-NS) has been created to measure the development of verbal, social and interactional skills of nursing students with patients, from their perspective in nursing care. The aim of the present study was to determine the construct validity and internal consistency reliability of the questionnaire. The study had a methodological and developmental design and was carried out in four steps: adjustment of the items, face validity, data collection and data analysis. The number of items was reduced from 48 to 31 . The factor analysis of the final 31 items resulted in four quite distinct factors: "Inviting to talk about feelings and thoughts", "Building a caring relationship", "Encouraging social and practical aspects in daily life" and "Caring towards health and wellbeing". The results showed satisfactory psychometric properties in terms of content validity, construct validity and the internal consistency reliability of the questionnaire. It could be concluded that the original conceptual model could serve as a theoretical foundation to explain and understand nurses' caring interactions with their patients.
\end{abstract}

Key Words: Instrument validation, Nurse-patient interactions, Nursing students, Verbal and social interaction nursing students, Reliability, Validity

\section{INTRODUCTION}

The article's focus is on the development of the nursing students' skills in establishing a caring relationship between themselves and the patients and performing different caring interactions through the use of the Verbal and Social Interaction for Nursing Students (VSI-NS) questionnaire. The items in this questionnaire have been adjusted from the original VSI (developed for psychiatric care) ${ }^{[1]}$ for the context of general care and to capture students' views on different nursing actions and skills during their education to nurses. The ba- sic assumptions for this research are the nurses' willingness to meet the patients by being present, open and compliant, showing respect, supporting mutuality and caring for them. In a caring relationship, the nurse has the responsibility to create conditions for changing, maintaining, starting or supporting the patients' health processes (cf Eriksson, 1987). ${ }^{[2]}$ According to Wiklund (2003), ${ }^{[3]}$ caring for the patients entails being a fellow human beeing, showing a willingness to establish a relationship and showing the patient that he or she is important and that the patients' thoughts, feelings and

*Correspondence: Mikael Rask; Email: mikael.rask@1nu.se; Address: School of Health and Caring Sciences, Linnaeus University, Växjö, Sweden. 
needs are of importance.

In the transition from being a nursing student to being a nurse, different types of knowledge and skills have to be developed. The nursing education aims to develop the nursing students' skills in communicating with the patients, being prepared to meet the patients suffering, being able to deal with and cope with different situations and problems in the interactions with the patients. This do not only deal with what the nursing student learns, but is also reflected in how the students' skills can be developed. Studies have showed that newly graduated nurses do not feel prepared for their role as nurses. Starting to work as a nurse can be experienced as a shock, ${ }^{[4-7]}$ and in particular the first year after graduation is perceived as being difficult, ${ }^{[8]}$ and the nurses feel nervous and afraid of not doing good work. ${ }^{[9]}$ In a study by Ferguson and Day, ${ }^{[10]}$ it was found that the nursing education did not sufficiently prepare the students for their responsibilities. Newly graduated nurses considered the theoretical education as well as the practical training to be insufficient and did not feel fully prepared for their work tasks. ${ }^{[1,12]}$ Furthermore, teachers in a nursing programme maintain that a good nurse has to be prepared and available to welcome others as persons and invite the patient to a relationship based on mutuality, respect, trust and empathy. ${ }^{[13]}$

The nurses caring could be described as an art with the aim of inviting and confirming the patients and their family members. The nurse-patient interaction, characterized by respect and participation especially in terms of decision-making, has been described as important in a number of studies. ${ }^{[14,15]}$ In a review by Rchaidia, Dierckx de Casterlé, De Blaeser and Gastmans, ${ }^{[16]}$ it was found that patients emphasize the importance of experiencing hope and support, and when children describe a good nurse they want someone who talks nicely and kindly to them, giving them encouragement and support and treating them with respect. ${ }^{[17]}$

The importance of the interaction between nurses and patients has been emphasized by nurses working in elderly care ${ }^{[18]}$ and also by the elderly themselves. ${ }^{[19]}$ The elderly patients describe a good nurse as having psychosocial competence, being able to support, showing an understanding and caring attitude, as well as being ready to establish a trustful relationship. From the perspective of the nurses, being a good nurse entails showing the patients dignity, respect and patience, helping them to feel safe based on developing a good relationship. ${ }^{[18]}$

Verbal and social interactions can be seen as a generic term for the actions nurses use in their daily work with their patients. As mentioned above, it is important to establish a caring nurse-patient relationship and this can be carried out by showing interest in the patients' individual life experiences, their social life as well as their practical life. By focusing on those aspects, it is possible for nurses to explore different ways to help the patient to manage their problems and difficulties. ${ }^{[20]}$ Thus, in the previous research, mentioned above, shows that nursing students meets challenges on different levels during their education and that their practical and interactional skills need to be focused during their education.

The VSI-NS originates from previous research in a number of different psychiatric care settings. ${ }^{[1,21,22]}$ The interactions that take place in the relationship between the nurses and the patients have been conceptualised in the form of a model, based on theory and philosophy relevant to psychiatric care and a set of questionnaires has been developed, ${ }^{[1,22]}$ termed Verbal and Social Interactions (VSI). The six categories in the original VSI questionnaire were: "To build and sustain relationships", "Supportive/encouraging interactions", "Social skills training", "Reality orientation", "Reflective interactions" and "Practical skills training". [1] The two first categories were described as the foundation for the other four categories. The conceptual model of VSI has been further tested by by using factor analysis. This analysis was used for further development and description of the conceptual model in three dimensions; To create a relationship based on support and encouragement. Focusing on the patients' inner world, feelings, experiences and behaviour. Focusing on the patients practical and social skills ${ }^{[21,22]}$ and the first dimension was the strongest factor. A further use of the questionnaire is for the assessment of the needs for in-house training among nurses in the psychiatric context. ${ }^{[1]}$

This present study is part of a larger research project with the aim of studying the development of the interactional skills of nursing students during their education. Questionnaire development includes investigating what is actually measured when using a questionnaire and how it can be practically applied in the intended context. A further stage in this process is thus to ascertain whether the category structure from earlier studies using the questionnaire can be upheld in the new context or whether other latent facets emerge. Exploratory factor analysis is commonly used for identifying any hidden or underlying patterns that can exist in a questionnaire. ${ }^{[23]}$ The study's aim was thus to investigate the reliability of the VSI-NS questionnaire in terms of its internal consistency as well as its construct validity.

\section{METHODS}

\subsection{Design}

The present study had a methodological and developmental design for construction of a questionnaire and was carried 
out in four steps: identifying/adjusting the items for the context, face validity, data collection and data analysis. The Ethical Advisory Board of Southeast Sweden was consulted about this study. An ethical self-review was performed and confirmed that no ethical approval from the committee was necessary for this study. However, to certify the ethical aspect the Ethical Advisory board (Dnr EPK 381-2016) inspected the study and no ethical obstacles were found. In accordance with the Declaration of Helsinki (2013), the 123 participants gave written consent after receiving written and verbal information about the study, containing its purpose and the procedures including the voluntary nature of participation and the option to withdraw at any time. The confidentiality of the participants was assured; no names or places are mentioned in the text.

\subsection{Development of the verbal and social interactions (VSI) questionnaire}

\subsubsection{Step 1: Adjusting items and construction of cate- gories}

The questionnaire, VSI was developed to survey patients' and nurses' views on the frequency and importance of nursing interactions in a variety of psychiatric care contexts. The contextual model of $\mathrm{VSI}^{[1]}$ and the suitability of the 50 items in the original VSI questionnaire were discussed within the research group, consisting of eight members all working within nursing education (six registered nurses one social scientist and one physiologist). This discussion led to adjustments and re-wording of the items as well as the exclusion of two items that were more relevant for the psychiatric care context, thus resulting in a 48 -item version of VSI-NS.

\subsubsection{Step 2: Face validity}

A test of a preliminary version was then carried out among a group of nursing students $(n=27)$. They completed the questionnaire and were also requested to perform a review of the items in the questionnaire in terms of relevance, clarity and readability. The review revealed that the items were seen to be relevant for the focus of the study. There was, however, a need for greater clarity and readability. A few items were then adjustedto avert any ambiguities and to discern between those with a similar content.

\subsubsection{Step 3: Data collection}

This part of the study was conducted among nursing students in their 1st semester at a university in southern Sweden. The total population in the 1st semester was 135 and 123 of these (91\%) completed the VSI-NS with 48 items (see Table 1). There were 105 female and 18 male students and the mean age was 25.1 years.

Published by Sciedu Press

\subsubsection{Step 4: Data analysis}

Construct validity and internal consistency were tested for by using the computer based programs FACTOR v.10.3.01 ${ }^{\text {[24] }}$ and SPSS 23.0 (SPSS Inc., Chicago, IL, USA).

\subsubsection{Construct validity}

A classical parallel analysis (PA) was conducted to determine the most suitable number of factors. ${ }^{[25]}$ Principal Componenet Analysis with orthogonal rotation of the Varimax type with Kaiser's normalization was used in the factor analysis. Factor extraction was based on an Eigenvalue $\geq 1$. $^{[26]}$ The number of items was reduced in order to minimise factorial complexity and multiple loadings. This was performed by excluding items that loaded $<.50$, and which in accordance with Hair, Anderson Tatham and Black ${ }^{[27]}$ are not considered practically significant.

Table 1. Demographic characteristics of 123 nursing students from a university in southern Sweden

\begin{tabular}{ll}
\hline Number & $\mathbf{1 2 3}$ \\
\hline Sex & \\
Female & 105 \\
Male & 18 \\
Age (years, mean) & 25.1 \\
\hline
\end{tabular}

\subsubsection{Internal consistency reliability}

The internal consistency was measured with Cronbach's alpha, and with regard to the development of a new questionnaire, the lowest value for Cronbach's alpha was set at .70. ${ }^{\text {[26] }}$

\section{RESULTS}

\subsection{Construct validity}

The optimal number of factors for the questionnaire was found to be four. The first factor analysis resulted in the extraction of eleven factors, accounting for approximately $71.1 \%$ of the total variance. All 48 items showed good communality $\geq .61$. Using the scree test (see Figure 1), four of the eleven extracted factors were regarded as significant (Hair et al. 1995), accounting for approximately $51.2 \%$ of the total variance. The remaining factors did not contribute to a useful interpretation of the structure. ${ }^{[28]}$ By applying the Classical parallel analysis ${ }^{[25]}$ it was also shown that a four factor solution was the most suitable. Only 31 items attained the criterion of a factor loading $>.50$ and the reduction of items, as suggested by Hair et al., ${ }^{[27]}$ contributed to minimizing factorial complexity and multiple loadings.

Thirty one items were then analysed revealing four distinct factors. The communality score for all items were deemed reasonably good at $\geq .41$ and the scree test showed a four factor solution (see Figure 2). An Eigenvalue $\geq$ two was achieved (see Table 2) and the cumulative variance was 
$58.2 \%$. The factor loadings for all the items were above (Eigenvalue-2.28) contained six items with an explained vari.50. Factor 1 (Eigenvalue-10.3) explained 33.3\% of the vari- ance of $7.4 \%$ and finally Factor 4 (Eigenvalue-2.0) included ance, containing twelve items. The seven items in Factor 2 six items and explained $6.6 \%$ of the variance. The results of (Eigenvalue-2.89) explained 9.3\% of the variance. Factor 3 the factor analysis are presented in Table 2.

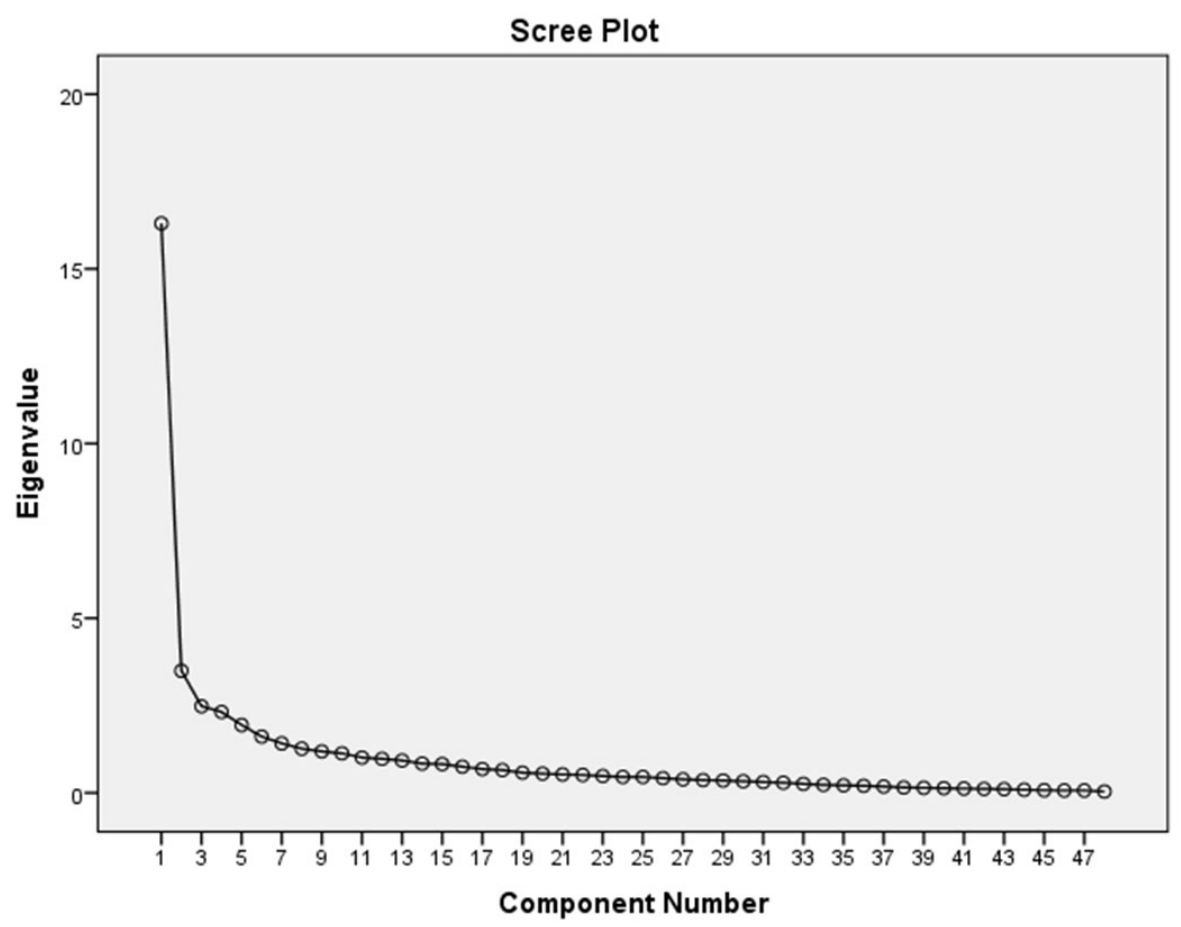

Figure 1. VSI-NS questionnaire with 48 items-Scree test

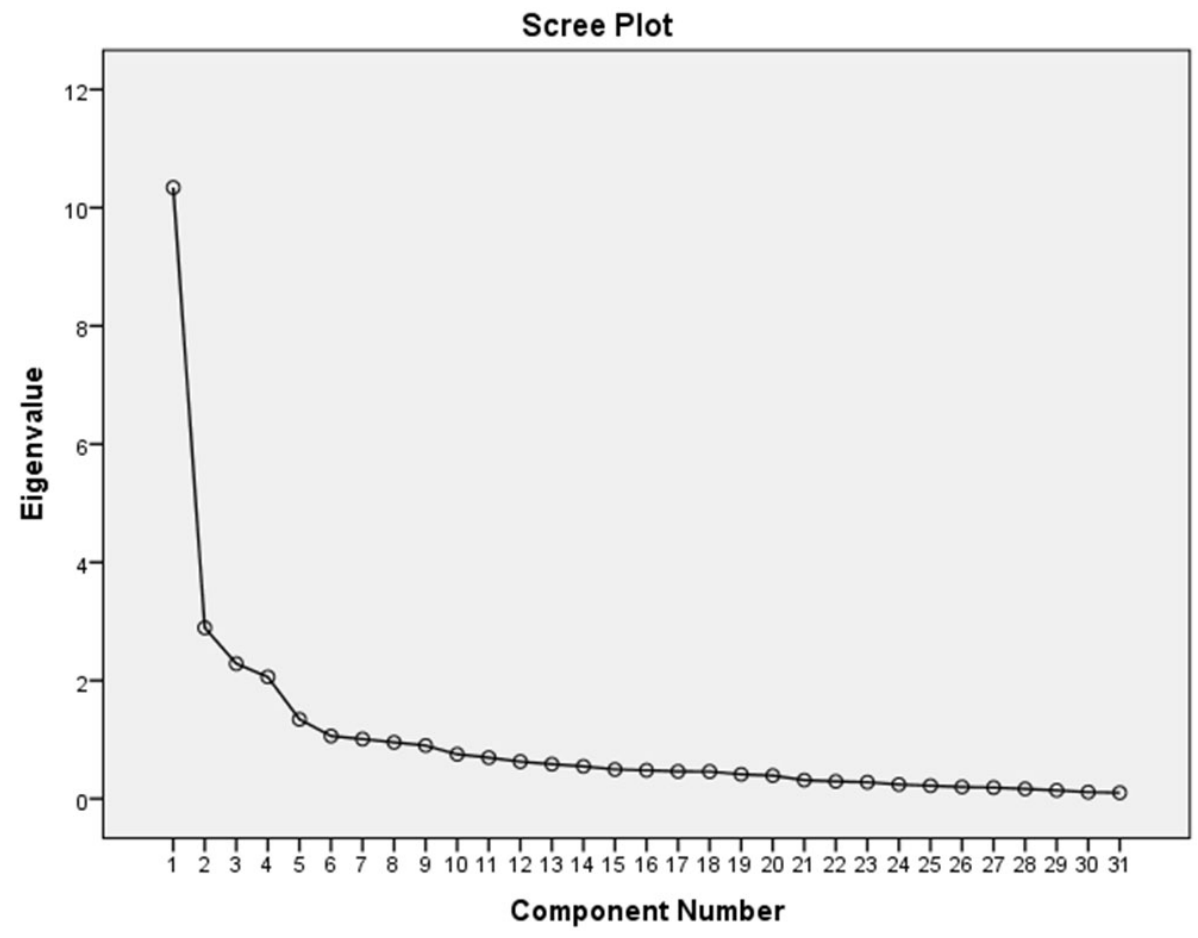

Figure 2. VSI-NS questionnaire with 31 items-Scree test 
Table 2. VSI-NS with 31 items $(n=123)$-Construct validity (factor analysis with principal component analysis, Varimax rotation) and internal consistency reliability (Cronbach's coefficient alpha)

\begin{tabular}{|c|c|c|c|c|}
\hline \multirow{2}{*}{ Factors and items } & \multicolumn{4}{|c|}{ Factor } \\
\hline & 1 & 2 & 3 & 4 \\
\hline \multicolumn{5}{|l|}{ Inviting to talk about feelings and thoughts } \\
\hline 31 "You talk to the patients about their sexuality" & .732 & & & \\
\hline 29 "You talk to the patients about how they think and feel about other people" & .694 & & & \\
\hline 35 "You talk to the patients about possible difficulties they have when being with other people" & .692 & & & \\
\hline $\begin{array}{l}27 \text { "You talk to the patients about things/situations that they experience as unpleasant and seems to make } \\
\text { them feel sad" }\end{array}$ & .642 & & & \\
\hline 28 "You talk to the patients about things/situations that they seem to experience as frightening" & .605 & & & \\
\hline 20 "You talk to the patients about things/situations that they seem to be embarrassed about or feel bad about" & .591 & & & \\
\hline 23 "You talk to the patients about situations they have experienced earlier in life" & .588 & & & \\
\hline 32 "You talk to the patients about how they perceive themselves" & .583 & & & \\
\hline 33 "You show interest in the patients' social situation in general” & .574 & & & \\
\hline 30 "You talk to the patients about their feelings" & .563 & & & \\
\hline 19 "You talk to the patients about things/situations that they seem to experience as unpleasant to talk about” & .528 & & & \\
\hline 24 "You talk to the patients about how they perceive their personal problems and difficulties" & .518 & & & \\
\hline
\end{tabular}

\section{Building a caring relationship}

3 "You show the patients that you are there for them"

2 "You show the patients that you want to get to know them" $\quad .760$

$\begin{array}{ll}1 \text { "You show the patients that you care about them" } & .754\end{array}$

5 "You show the patients that they can trust you" $\quad .721$

4 "You show the patients that you have time for them and want to make contact with them" $\quad .713$

6 "You show the patients that you are honest" $\quad .680$

14 "You remind the patients about positive experiences from their past" $\quad .561$

Encouraging social and practical aspects in daily life

38 "You encourage the patients to do things together with other people" .829

39 "You encourage the patients to take part in group activities"

37 "You encourage the patients to keep in contact with their relatives and friends” $\quad .792$

46 "You encourage the patients to learn new practical skills” .618

44 "You encourage/support patients in coping with daily life through routines and keeping things in order that they need"

\begin{tabular}{llll}
\hline 34 "You talk to the patients about their experiences of being together with other people" & .521 & .527 \\
\hline Caring towards health and well-being &
\end{tabular}

\begin{tabular}{|c|c|c|c|c|}
\hline 41 "You support patients to do physical exercise that benefits their health and well-being" & & & & .687 \\
\hline 40 "You inform and support patients to eat and drink healthily" & & & & .678 \\
\hline 45 "You talk to the patients about how they can manage their medication" & & & & .661 \\
\hline 25 "You talk to the patients about how they experience their illness" & & & & .661 \\
\hline 26 "You talk to the patients about how they/you can together find solutions to enhance their well-being" & & & & .571 \\
\hline 48 "You talk to the patients about how they sleep" & & & & .549 \\
\hline Cronbach's coefficient $\alpha$ & $>.89$ & $>.87$ & $>.86$ & $>.81$ \\
\hline Eigenvalue & 10.3 & 2.89 & 2.28 & 2.06 \\
\hline \% of variance explained (total = 58.2\%) & 33.3 & 9.33 & 7.37 & 6.64 \\
\hline Alpha entire scale $=.93$ & & & & \\
\hline
\end{tabular}




\subsection{Internal consistency reliability}

Cronbach's $\alpha$ for the four factors was $0.89,0.87,0.86$ and 0.81 thus confirming a good internal consistency for each of the factors in the 31-item version.

\subsection{Interpretation of the four factors}

The possible underlying pattern of the items in the factors revealed four quite clear and meaningful groups of nursing actions. The six categories from the conceptual model of $\mathrm{VSI}^{[1]}$ were used as a guide for interpreting the four factors. The content of the 31 items appears to be able to reveal what the nursing students' belive to be the focus of their future work and not only the actions and interactions the nursing students' belive they will perform after graduation. When interpreting and understanding the content of each factor, the meaning also comes closer to being able to shed light on the focus that the nursing students' belive they will have in their future work. The first factor seems to reflect the interest in focusing on the patient's inner world of thoughts and feelings. The second factor reflects the mutual and safe relationship between the nurse and the patient. The third factor reflects the more social and practical aspects of the patients' daily life while the fourth factor has a clearer focus on what to do to promote health and wellbeing.

\subsubsection{Factor one-Inviting to talk about feelings and thoughts}

The nurses' aim to gain knowledge about how the patient's feelings, thoughts and personal or private matters can impact the latter's possibilities for recovery appears to be represented in this factor. The actions include talking about the feelings and thoughts the patients experience as difficult, frightening or unpleasant to talk about. This factor also includes actions that are directed at the way the patient reacts in various situations, and especially in relation to others.

\subsubsection{Factor two-Building a caring relationship}

The aim of helping the patient to feel that the nurse wants to create a caring atmosphere through her/his caring interactions is highlighted in this factor. These interactions include an ability to create such an atmosphere by demonstrating that their wish to both make contact with and get to know the patient. The nurses thus have to show that they are available and that the patients can trust them. A possible interpretation could be that the nursing students are willing to create a supportive and caring relationship with the patients.

\subsubsection{Factor three-Encouraging social and practical as- pects in daily life}

Examples of interactions, which nurses can be used by the nurses to encourage the patient to discover how their social activities can benefit them in their health process constitute part of this factor. The nurses focus on the patients' practical skills and the development of routines so that a patient will be able feel that he/she can gain a sense of control over situations in everyday life, are also highlighted. A possible interpretation could be that the nursing students' are focusing on the importance of the patients having a healthy social network.

\subsection{Factor four-Caring towards health and wellbeing}

The focus in this factor is related to the patients' ill health, health as well as their wellbeing. The nursing students are focusing on healthy physical exercise, what the patient can eat and drink to support their health process as well as how they can manage medications. The nursing students also focus on how the patients experience their illness and how to enhance their wellbeing. A possible interpretation could be that the students' find that the patients' experiences of their illness in combination with more practical matters are important when trying to find the balance between ill-health and wellbeing.

\section{Discussion}

The factor structure in the VSI-NS' 31 -item version reveals a somewhat different pattern than be found in the conceptual model's six categories ${ }^{[1]}$ as well as in the description of the three dimensions described in Rask, Brunt and Fridlund. ${ }^{[21]}$ The first factor resembles two of the categories in the original VSI questionnaire 'Reflective interactions' and 'Reality orientation'. The second factor has several similarities with the category 'To build and sustain relationships'. The third factor is, to its content, a mixture of the two categories 'Social skills training' and 'Practical skills training'. The fourth and final factor constitutes a new factor that was not found as a category in the original conceptual model and may well be more representative of the non-psychiatric care context in the present study. The results of the present study thus appear to confirm that the first, second and third factors are constant, both statistically and theoretically. A confirmatory factor analysis ${ }^{[26]}$ or a Rasch-analysis ${ }^{[29]}$ could be appropriate methods for further establishing the possible association between the VSI-NS questionnaire and the conceptual model.

\subsection{Validity}

The questionnaire's content validity is strengthened by the items having an empirical as well as a theoretical and philosophical foundation in nurses' caring interactions, ${ }^{[1]}$ and also by the comments provided by the nursing students in the face validity study. Construct validity and item reduction with explorative factor analysis is a statistical method facilitating the identification of potential underlying patterns within a questionnaire. ${ }^{[23]}$ This method appeared to be suitable with 
satisfactory levels of explained variance and the emergence of discernible factors.

The first extracted factor in a factor analysis can be understood as the core factor. ${ }^{[26]}$ In previous studies in psychiatric care contexts, ${ }^{[1,20-22]}$ the corresponding core factors focused on the creation of relationships based on support and encouragement. It could thus be seen to be somewhat surprising that the first extracted factor in the present study was "Inviting to talk about feelings and thoughts". The content of the second factor in the present study "building a caring relationship", however, resembles the content of these aforementioned core factors with its focus on a caring relationship. A possible interpretation of this difference could be that the nursing students in the present study have not fully understood the central role of the caring relationship in the same way as experienced, qualified nurses have done in the other studies. The nursing students are at the beginning of the developing process of becoming nurses and may well not have comprehended the need to establish a relationship prior to inviting a patient to talk about feelings and thoughts. To confirm whether this a correct interpretation an explorative factor analysis, based on data from nursing students in their final semester and fully qualified nurses working for at least one year, could be performed.

\subsection{Reliability}

The reliability of the 31-item VSI-NS questionnaire, measured in terms of its internal consistency, can be considered to be adequate with a Cronbach's coefficient alpha of 0.93 for the whole questionnaire. A Cronbach's alpha for a developing questionnaire should exceed 0.70 or for a more established questionnaire $0.80 .{ }^{[26]}$ The four factors demonstrated good internal consistency with Cronbach's alpha between 0.81 and 0.89 , thus indicating that these four factors measure four distinct dimensions of the nursing actions that nursing students see as the focus for their interactions with the patients in their daily work.

\section{CONCLUSIONS AND IMPLICATIONS}

The investigation of the first version of the VSI-NS questionnaire (with 48 items) in this study revealed a "hidden" structure with four distinct factors (with 31 items). The content of these four factors could be used to describe the nurses' focus in their work in general care. Thus, when using the VSI-NS questionnaire, with the 31 items, the theoretical foundation behind the conceptual model with the six categories could be used to explain and understand nurses' caring interactions with their patients. Furthermore, it is possible to use the 31-item questionnaire (presented in this article) for investigating what the nursing students have as a focus in their nurse-patient interactions during their education.

The results of the current study reveal that the reduced 31item version of VSI-NS demonstrates good psychometric properties where content validity, construct validity and the homogeneity are concerned. Larger studies that focus on concurrent validity and test-retest reliability for further establishing validity and reliability are, however, also needed. A Rash-analysis ${ }^{[29]}$ or a confirmatory factor analysis could be used to further establish the construct validity of the possible association between VSI-NS and the conceptual model of VSI. ${ }^{[26]}$ A further measure for establishing the stability of the questionnaire could be studies performed in different contexts and by different researchers.

The implications for practice are that the VSI-31 could be helpful for teachers in nursing education in identifying areas of interactional skills where nursing students need to develop and improve. The VSI-31 could also be used to follow the progress of nursing students and their development of caring interaction skills during their education at Bachelor level as well as for comparing with the Specialist Nursing Programmes at advanced level or between the students on advanced level programmes.

\section{ACKNOWLedgements}

Thanks to the School of Health and Caring Sciences, Linnaeus University, Sweden, for supporting this study.

\section{CONFLICTS OF INTEREST DISCLOSURE}

The authors report no conflicts of interest.

\section{REFERENCES}

[1] Rask M, Brunt D. Verbal and social interactions in the nurse-patient relationship in forensic psychiatric nursing care-a model and its philosophical and theoretical foundation. Nursing Inquiry. 2007; 14(2): 169-176. https://doi.org/10.1111/j.1440-1800.2007.003 $64 . x$

[2] Eriksson K. Vårdandets idé. (Swedish) The idea of caring. Stockholm:

\section{Almqvist \& Wiksell. 1987}

[3] Wiklund L. Vårdvetenskap i klinisk praxis (Swedish). Caring Science in clinical praxis. Stockholm: Natur och kultur. 2003.

[4] Bisholt B. Nyexaminerade sjuksköterskors yrkessocialisering - Erfarenheter av ett introduktionsprogram. (Swedish) (The professional socialisation of newly graduated nurses-Experiences of an introduc- 
tion programme.) Doctoral dissertation. Schhool of Caring Science and Health, Gothenburg University. 2009.

[5] Watt E, Pascoe E. An exploration of graduate nurses' perceptions of their Preparedness for practice after undertaking the final year of their bachelor of nursing degree in a university-based clinical school of nursing. International Journal Of Nursing Practice. 2013; 19(1): 23-30. https://doi.org/10.1111/ijn. 12032

[6] Duchscher JEB. Critical thinking: perceptions of newly graduated female baccalaureate nurses. Journal of Nursing Education. 2003; 42(1): 1-12.

[7] Duchscher JEB. Transition shock: the initial stage of role adaptation for newly graduated Registered Nurses. Journal of Advanced Nursing. 2009; 65(5): 1103-1113. https://doi.org/10.1111/j.1365-2 648.2008.04898. $\mathrm{x}$

[8] Wangensteen S, Johansson IS, Nordström G. The first year as a graduate nurse an experience of growth and development. Journal of Clinical Nursing. 2008; 17: 1877-1885. https ://doi.org/10.1 $111 / j .1365-2702.2007 .02229 . x$

[9] Delaney C. Walking a Fine Line: Graduate Nurses' Transition Experiences During Orientation. Journal of Nursing Education. 2003; 42(10): 437-443.

[10] Ferguson L, Day R. Challenges for new nurses in evidence-based practice. Journal of Nursing Management. 2007; 15: 107-113. https://doi.org/10.1111/j.1365-2934.2006.00638.x

[11] Ross H, Clifford K. Research as a catalyst for change: the transition from student to Registered Nurse. Journal Of Clinical Nursing. 2002; 11(4): 545-553. https://doi.org/10.1046/j.1365-2702. 20 $02.00610 . \mathrm{x}$

[12] Feng R, Tsai Y. Socialisation of new graduate nurses to practicing nurses. Journal of Clinical Nursing. 2012; 21(13): 2064-2071. https://doi.org/10.1111/j.1365-2702.2011.03992.x

[13] De Araujo Sartorio N, Pavone Zoboli EL. Images of a good nurse presented by teaching staff. Nursing Ethics. 2010 Nov; 17(6): 687-94. https://doi.org/10.1177/0969733010378930

[14] Schröder A, Ahlström G, Larsson BW. Patients' perceptions of the concept of the quality of care in the psychiatric setting: a phenomenographic study. Journal of Clinical Nursing. 2006 Jan; 15(1): 93-102. https://doi.org/10.1111/j.1365-2702.2005.01241.x

[15] Browall M, Koinberg I, Falk H, et al. Patients' experience of important factors in the healthcare environment in oncology care. International Journal of Qualitative Studies on Health \& Well-being. 2013 Aug 6; 8: 20870.

[16] Rchaidia L, Dierckx de Casterlé B, De Blaeser L, et al. Cancer patients' perceptions of the good nurse: a literature review. Nursing Ethics. 2009 Sep; 16(5): 528-42. https://doi .org/10.1177/09 69733009106647
[17] Brady M. Hospitalized children's views of the good nurse. Nursing Ethics. 2009 Sep; 16(5): 543-60. https ://doi.org/10.1177/09 69733009106648

[18] Wadensten B, Engholm R, Fahlström G, et al. Nursing staff's description of a good encounter in nursing homes. International Journal of Older People Nursing. 2009 Sep; 4(3): 203-10. https: //doi.org/10.1111/j.1748-3743.2009.00170.x

[19] Van der Elst E, Dierckx de Casterlé B, Gastmans C. Elderly patients' and residents' perceptions of the good nurse: a literature review. Journal of Medical Ethics. 2012 Feb; 38(2): 93-7. https : //doi.org/10.1136/medethics-2011-100046

[20] Rask M, Brunt D. Vårdande och stödjande handlingar inom psykiatriska vård-och boendeformer (Swedish). Lund: Studentlitteratur, 2010 (Polen). Caring and supportive interactions in psychiatric care and housing. 2010.

[21] Rask M, Brunt D, Fridlund B. Validation of the verbal and social interaction questionnaire: nurses' focus in the nurse-patient relationship in forensic nursing care. Journal of Psychiatric and Mental Health Nursing. 2008; 15: 710-716. https://doi .org/10.1111/ $\mathrm{j} .1365-2850.2008 .01292 . \mathrm{x}$

[22] Brunt D, Rask M. Validation of the Verbal and Social Interaction questionnaire: carers' focus in the carer-resident relationship in supported housing facilities for persons with psychiatric disabilities (VSI-SH). Journal of Psychiatric and Mental Health Nursing. 2013; 20: 279-285. https://doi.org/10.1111/j.1365-2850.2012.01925.x

[23] Andreasson S. Factor Analysis, an Introduction (in Swedish). Department of Nursing Science, Faculty of Health Sciences, Linköping University, Linköping. 1993.

[24] Lorenzo-Seva U, Ferrando PJ. FACTOR: A computer program to fit the exploratory factor analysis model. Behavioral Research Methods, Instruments and Computers. 2006; 38(1): 88-91. https : //doi.org/10.3758/BF03192753

[25] Horn JL. A rationale and test for the number of factors in factor analysis. Psychometrika. 1965; 30: 179-185. https ://doi.org/ 10.1007/BF02289447

[26] Rattray J, Jones MC. Essential elements of questionnaire design and development. Journal of Clinical Nursing. 2007; 16: 234-243. https://doi.org/10.1111/j.1365-2702.2006.01573.x

[27] Hair JF, Anderson RE, Tatham RL, et al. Multivariate Data Analysis with Readings, 4th edn. Prentice Hall, Englewood Cliffs. 1995.

[28] Kerlinger F. Foundations of Behavioural Research, 3rd edn. Holt, Rinehart and Winston, New York. 1986.

[29] Andrich DA. A rating scale formulation for ordered response categories. Psychometrika. 1978; 43: 561-73. https ://doi.org/10.1 007/BF02293814 